University of Nebraska - Lincoln

DigitalCommons@University of Nebraska - Lincoln

4-2002

\title{
Case-Control Study of Attention-Deficit Hyperactivity Disorder and Maternal Smoking, Alcohol Use, and Drug Use During Pregnancy
}

Eric Mick

Harvard Medical School

Joseph Biederman

Harvard Medical School, biederman@helix.mgh.harvard.edu

Stephen V. Faraone

Harvard Medical School, sfaraone@hms.harvard.edu

Julie Sayer

Massachusetts General Hospital

Seth Kleinman

Massachusetts General Hospital, seth.kleinman@kayescholer.com

Follow this and additional works at: https://digitalcommons.unl.edu/veterans

Mick, Eric; Biederman, Joseph; Faraone, Stephen V.; Sayer, Julie; and Kleinman, Seth, "Case-Control Study of Attention-Deficit Hyperactivity Disorder and Maternal Smoking, Alcohol Use, and Drug Use During Pregnancy" (2002). U.S. Department of Veterans Affairs Staff Publications. 55.

https://digitalcommons.unl.edu/veterans/55

This Article is brought to you for free and open access by the U.S. Department of Veterans Affairs at DigitalCommons@University of Nebraska - Lincoln. It has been accepted for inclusion in U.S. Department of Veterans Affairs Staff Publications by an authorized administrator of DigitalCommons@University of Nebraska - Lincoln. 


\title{
Case-Control Study of Attention-Deficit Hyperactivity Disorder and Maternal Smoking, Alcohol Use, and Drug Use During Pregnancy
}

\author{
ERIC MICK, SC.D., JOSEPH BIEDERMAN, M.D., STEPHEN V. FARAONE, PH.D., \\ JULIE SAYER, B.A., AND SETH KLEINMAN, M.S.W.
}

\begin{abstract}
Objective: To address the putative association between attention-deficit hyperactivity disorder (ADHD) and prenatal exposure to maternal cigarette smoking, drugs of abuse, and alcohol attending to potential confounding by familial ADHD, maternal depression, conduct disorder, and indicators of social adversity in the environment. Method: A retrospective, hospital-based, case-control study was conducted with 280 ADHD cases and 242 non-ADHD controls of both genders. The case and control children and their relatives were systematically assessed with structured diagnostic interviews. Logistic regression analysis was used to determine the adjusted effect of prenatal exposure to substance use and ADHD. Results: ADHD cases were 2.1 times (95\% confidence interval $=1.1-4.1 ; p=.02$ ) more likely to have been exposed to cigarettes and 2.5 times (95\% confidence interval $=1.1-5.5 ; p=.03$ ) more likely to have been exposed to alcohol in utero than were the non-ADHD control subjects. Adjustment by familial psychopathology, Rutter's indicators of social adversity, and comorbid conduct disorder did not account for the effect of prenatal exposure to alcohol or the products of cigarettes. Conclusions: ADHD may be an additional deleterious outcome associated with prenatal exposure to alcohol independently of the association between prenatal exposure to nicotine and smoke products and other familial risk factors for the disorder. J. Am. Acad. Child Adolesc. Psychiatry, 2002, 41(4):378-385. Key Words: attention-deficit hyperactivity disorder, pregnancy, substance abuse, cigarette smoking.
\end{abstract}

Attention-deficit hyperactivity disorder (ADHD) is a common childhood psychiatric disorder with a prevalence of 3\% to 5\% in the United States (Shaffer et al., 1996). Both genes and environmental risk factors influence the etiology of ADHD (Biederman et al., 1995a; Breslau et al., 1996; Faraone et al., 1999; LaHoste et al., 1996; Milberger et al., 1997; Sprich-Buckminster et al., 1993; Swanson et al., 1998). Prenatal exposure to maternal tobacco smoking is a relatively recent addition to previously documented risk factors for ADHD. For example,

\footnotetext{
Accepted October 16, 2001.

From the Department of Psychiatry, Harvard Medical School, Boston (J.B., S. V.F,, E.M.); Pediatric Psychopharmacology Unit, Massachusetts General Hospital, Boston (E.M., J.B., J.S., S.K., S.V.F.); and Harvard Institute of Psychiatric Epidemiology and Genetics at Brockton-West Roxbury Veterans Affairs Medical Center and Massachusetts Health Center, Boston (S.V.F.).

This work was supported by NIMH grant RO1 MH41314-07 (J.B.).

Correspondence to Dr. Mick, Massachusetts General Hospital-Pediatric Psychopharmacology Research, 15 Parkman Street, WACC 725, Boston, MA 02114 .

0890-8567/02/4104-0378@ 2002 by the American Academy of Child and Adolescent Psychiatry.
}

Milberger et al. $(1996,1998)$ found a 2.7-fold increased risk for ADHD associated with maternal smoking in 140 cases and 120 controls and a 4.4-fold increased risk for ADHD in their 303 high-risk siblings. Landgren et al. (1998) reported a 3-fold increased risk for a syndrome studied in Nordic countries that is characterized by deficits in attention, motor control, and perception (DAMP) and overlaps with ADHD considerably. Weissman et al. (1999) also reported a 2-fold increased risk for ADHD associated with prenatal exposure to tobacco use but did not demonstrate statistical significance because of a potential lack of statistical power $(N=50$ exposed and 97 nonexposed subjects).

Prenatal exposure to alcohol and drugs of abuse may also be associated with symptoms of ADHD. For example, children with fetal alcohol syndrome tend to be hyperactive, exhibit cognitive deficits and deficits in adaptive behavior, and are at increased risk for psychiatric disorders (Aronson et al., 1985; Coles et al., 1991; Nanson and Hiscock, 1990; Streissguth et al., 1994). Although 
ADHD and fetal alcohol syndrome are clearly separate clinical entities (Nanson and Hiscock, 1990), the similarity in the presentation of ADHD and the ADHD-like behavioral component of fetal alcohol syndrome suggests that alcohol may also play a role in the etiology of ADHD (Coles et al., 1997). Although less is known about the short- or long-term consequences of prenatal exposure to other substances such as marijuana or cocaine (Richardson et al., 1993), children exposed prenatally to cocaine have demonstrated decreased visual attention and those exposed to marijuana use prenatally have been shown to exhibit impaired intellectual functioning (Day et al., 1994; Heffelfinger et al., 1997). Since cigarette smoking and substance use are often related to each other, it is not known whether the reported effects of prenatal exposure to cigarettes are independent of the effects of alcohol and drugs on attention and cognition.

Because $\mathrm{ADHD}$ is frequently comorbid with conduct disorder (CD) (Angold et al., 1999; Biederman et al., 1991) and maternal smoking during pregnancy has been shown to exert a 2- to 4-fold increased risk for CD (Ernst et al., 2001; Fergusson et al., 1998; Wakschlag et al., 1997; Weissman et al., 1999), this comorbidity may also confound studies of maternal smoking during pregnancy and ADHD. Because ADHD, CD, substance use disorders, and antisocial personality disorder (ASPD) are known to be comorbid with one another and to coaggregate in families (Biederman et al., 1995b, 1998; Boyle and Pickles, 1997; Chilcoat and Breslau, 1997; Faraone et al., 1995; Wilens et al., 1997, 1998), the putative link between prenatal nicotine exposure and ADHD might be mediated by another disorder. For example, Weissman et al. (1999) adjusted for parental psychiatric diagnoses (other than ADHD), while Milberger et al. (1996, 1998) did not adjust for comorbid CD or ASPD in the previous studies documenting an increased risk for ADHD in offspring. Therefore, the negative findings of Weissman et al. (1999) with regard to ADHD may have resulted from the statistical control for CD rather than a lack of statistical power. Thus the relationship between ADHD and maternal smoking during pregnancy needs to be revisited with attention to these potential confounders.

A number of studies have shown the male fetus to be more sensitive to intrauterine and other perinatal circumstances contributing to CNS disorders (e.g., Ernst et al., 2001; McCartney et al., 1999; O'Callaghan et al., 1992). Although previous work suggested that gender may not modify the relationship between maternal smok- ing during pregnancy and ADHD (Milberger et al., 1998), it has been shown to modify the relationship between $\mathrm{CD}$ and maternal smoking during pregnancy (Fergusson et al., 1998; Weissman et al., 1999). Inasmuch as the previous reports (Milberger et al., 1998) examining interactions between gender and prenatal exposure to cigarettes had relatively few female subjects with $\mathrm{ADHD}$, the effects of gender need to be examined further.

Fergusson et al. (1998) hypothesized that maternal smoking during pregnancy may be a marker for social disadvantage and that it is this adversity that accounts for the increased risk of disruptive behavior disorders in children prenatally exposed to nicotine and smoke products. Contrary to their hypothesis, however, they found that the relationship between maternal smoking during pregnancy and psychopathology in their children persisted even after statistically controlling for an extensive array of social risk factors. Nonetheless, the relationship between prenatal exposure to cigarettes and ADHD must be evaluated in light of possible associations between exposure status and related social factors. As in previous research, here we use six factors identified by Rutter (Rutter et al., 1975; Rutter and Quinton, 1977) as being associated with childhood mental disturbances (severe marital discord, low social class, large family size, paternal criminality, maternal mental disorder, and foster care placement) as an indicator of social adversity.

The goal of this report was to address the putative association between $\mathrm{ADHD}$ and prenatal exposure to maternal cigarette smoking, drugs of abuse, and alcohol with attention to potential confounding by familial ADHD, maternal depression, $\mathrm{CD}$, and indicators of social adversity in the environment. To this end, we analyzed data from a case-control study of boys and girls with ADHD to estimate the increased risk for ADHD associated with maternal cigarettes, alcohol, and drugs. We predicted that maternal cigarette smoking during pregnancy would be associated with ADHD and that this effect would not be modified by gender. We also predicted that there would be an association between maternal alcohol and drug use and ADHD.

\section{METHOD}

\section{Subjects}

In this analysis the data from two identically designed hospital-based case-control family studies of ADHD were combined (Biederman et al., 1996, 1999). The first study ascertained families on the basis of a male case or control child aged 6-17 years at the time of ascertainment. The second ascertained families on the basis of a female 
case or control child also aged 6-17 years at the time of ascertainment. As we have reported previously (Biederman et al., 2002), these samples were not significantly different on any demographic variables, except that the female subjects were slightly older than the male subjects $(11.0 \pm 3.3$ versus $11.7 \pm 3.2$ years of age $)$.

All of the ADHD subjects had a lifetime history which met full $D S M-I I I-R$ diagnostic criteria for ADHD according to a structured diagnostic interview (described in detail under "Measures"). We identified subjects from lists of referred ADHD patients from the pediatric psychopharmacology clinic at the Massachusetts General Hospital and from lists of children having evidence of ADHD in the computerized medical record of a health maintenance organization.

Within each setting, we selected non-ADHD controls from lists of outpatients at pediatric medical clinics of each institution. Controls were screened only for the absence of ADHD and were not excluded on the basis of any other diagnosis. The goal in selecting controls was to satisfy the comparability principles required for meaningful inferences in case-control epidemiological studies (Wacholder et al., $1992 \mathrm{a}-\mathrm{c})$. Because clinically referred subjects do not usually represent a clearly defined geographical area, controls were selected from nonrelated clinics of the same referral source with the assumption that, had they developed ADHD, the controls would return to the same institution for treatment of this new condition. The use of secondary study bases limits generalizability and does not produce a representative sample from a geographical population. Nevertheless, it does allow for meaningful case-control comparisons if the controls are individuals who could have been cases had they developed the disorder of interest during the time of the investigation (Wacholder et al., 1992a-c). Because controls are selected on the basis of a negative history of the disorder being studied, this assumption can never be truly validated. It is implicit, however, in all comparative research studies of referred cases.

Proband children and each of their first-degree relatives (mothers, fathers, and siblings older than 6 years of age) were interviewed to assess the lifetime and current history of psychopathology and were administered cognitive batteries to assess intelligence, achievement, and learning disorders (measures described below). All study procedures were approved by our institutional review board and all subjects provided written informed consent.

\section{Measures}

Psychiatric assessments of children and adolescents relied on the Schedule for Affective Disorders and Schizophrenia for School-Age Children-Epidemiologic version (K-SADS-E) (Ambrosini, 2000), and diagnostic assessments of parents relied on direct interviews with each parent using the Structured Clinical Interview for DSM-III-R (SCID) (Spitzer et al., 1990, 1992). To assess childhood diagnoses in the parents, we administered modules from the K-SADS-E covering childhood diagnoses. All assessments were made by raters who were blind to the child's diagnosis (ADHD or non-ADHD control) and ascertainment site. The mother's direct interview about her own psychopathology was conducted before and on a different day from the indirect interview she completed regarding psychopathology in her children. Different interviewers met with mothers and children to maintain blindness to case-control status and to prevent information from one informant influencing the assessment of the other.

Psychiatric diagnoses were assigned on the basis of DSM-III-R diagnostic criteria. Interviews were conducted by raters with undergraduate degrees in psychology who had been trained to high levels of interrater reliability. We computed $\kappa$ coefficients of agreement between raters and three experienced, board-certified, child and adult psychiatrists who listened to audiotaped interviews made by the raters. Based on 173 interviews, the median $\kappa$ was 0.86 ; $\kappa$ was 0.99 for ADHD and 0.93 for CD. Intellectual functioning was assessed with the Vocabulary, Block Design, Digit Span, and Digit Symbol subtests of the WISC-R (Wechsler, 1974). We estimated Full Scale IQ from the Vocabulary and Block Design subtests (Sattler, 1988). Socioeconomic status (SES) was measured with Hollingshead's four-factor index (Hollingshead, 1975).

We also performed analyses based on those adversity indicators identified in Rutter's work (Rutter et al., 1975; Rutter and Quinton, 1977) as being associated with childhood mental disturbances: severe marital discord, low social class, large family size, paternal criminality, maternal mental disorder, and foster care placement. Because none of our subjects had been placed in foster homes, the variable of foster care placement could not be used in our analysis. Low social class was defined as the lowest two groups of socioeconomic class in our sample (SES III and SES IV) (Hollingshead, 1975). Large family size was defined as three or more children. A history of antisocial personality in the father was used to index paternal criminality. Maternal mental disorder was considered present if the mother had at least two psychiatric disorders during the child's lifetime. Marital discord was derived from Family Conflict subscale of the Family Environment Scale (Moos, 1985). Our operational definitions of Rutter's indicators were added together to create a total index categorized by 0,1 , 2 , or 3 or more indicators of adversity.

Because this is a retrospective case-control study that relied on selfreport, the measurement of exposure was susceptible to error. To improve the reliability and precision of our estimates of relative risk, however, we used two measures of prenatal exposure to alcohol and drugs. In the first, mothers were directly questioned regarding the pregnancy, delivery, and infancy complications they experienced with the index child during the structured diagnostic interview they completed pertaining to the child's psychiatric history. Among these questions, there were direct questions regarding exposure to cigarettes, alcohol, or drugs. The second measure of exposure was derived from the mother's self-reported structured diagnostic interview regarding her own psychiatric history which included an assessment of alcohol and drug abuse or dependence. Using the reported onsets and offsets of drug and alcohol abuse or dependence in mothers, in combination with the date of birth of the index child, we determined whether cases and controls were exposed to alcohol or drugs during fetal development according to this second, indirect assessment of exposure.

\section{Data Analysis}

Horton et al. (1999) described a variety of methods to analyze multiple measures of a risk factor in epidemiological studies. Consistent with their suggestions, we used bivariate logistic regression (to simultaneously fit two logistic regression models - one for each source of information) predicting case-control status from the main effect of exposure, the main effect of the source of information (direct questioning or derived from mother's interview), and the interaction between exposure and source of information. If there was no statistically significant interaction between exposure and the source of information, we should conclude that the relationship between exposure and outcome is not sensitive to the source of the information and some combination of the measures of exposure may be used (Horton et al., 1999). In the absence of a statistically significant interaction, we remove interaction terms and report a single odds ratio for prenatal exposure to alcohol or drugs generated from the bivariate logistic regression model which uses information from both sources.

Because this results in more than one observation per subject, generalized estimating equations (Liang and Zeger, 1986) were used to 
fit logistic regression models with a working correlation structure and empirical estimates of variance to produce consistent standard errors and $p$ values. These models are commonly use in longitudinal studies when each subject is followed and provides more than one observation. They are necessary so that the number of subjects and not the number of observations is used to estimate statistical significance. The Wald $\chi^{2}$ was used to test statistical significance of the coefficients of these models. For those variables that were not repeated measurements, the Pearson $\chi^{2}$ and $t$ test were used to perform statistical tests comparing $\mathrm{ADHD}$ and non-ADHD groups for categorical and continuous data, respectively. All tests were two-tailed with $\alpha$ set at .05 .

\section{RESULTS}

There were $280 \mathrm{ADHD}$ cases and 242 non-ADHD control subjects. By design, there was no difference in the gender distribution of the two groups. There were small but statistically significant differences in age and SES, with ADHD subjects slightly younger and from middle class as opposed to the highest category of SES (Table 1). Mothers of ADHD cases were slightly younger than mothers of controls at the time of the subject's birth. There was also an increased lifetime prevalence of ADHD and $\mathrm{CD} / \mathrm{ASPD}$ in the parents of cases relative to the parents of controls (Table 1).
The different definitions of prenatal exposure to cigarettes, alcohol, and drugs are presented in Table 2. We fit bivariate logistic regression models with the dependent variable (case-control status) paired with the separate reports of exposure (to alcohol and drugs), the interaction between the source of information and measure of exposure, exposure to cigarettes, and potential confounders (maternal age at child's birth, indicators of social adversity, parental history of ADHD, parental history of CD/ASPD, and comorbid CD in cases and controls). For both alcohol (Wald $\chi^{2}{ }_{1}<0.01, p=.9$ ) and drugs (Wald $\chi_{1}^{2}=0.01, p=.9$ ), there was no significant interaction between the exposure and the source of information. This indicated that the relationship between exposure and ADHD was not sensitive to the source of information and that both measures described some component of the true, but unobserved, level of exposure to alcohol and drugs during pregnancy (Horton et al., 1999). Thus the results from the models with the interaction terms dropped are presented in Table 3.

This analysis indicated that ADHD cases were significantly more likely to have been exposed to cigarettes and alcohol in utero than were the non-ADHD control sub-

TABLE 1

Subject and Parental Characteristics

\begin{tabular}{|c|c|c|c|}
\hline & $\begin{array}{c}\text { ADHD } \\
\text { Cases } \\
(n=280)\end{array}$ & $\begin{array}{c}\text { Non-ADHD } \\
\text { Controls } \\
(n=242)\end{array}$ & $\begin{array}{c}\text { Statistical } \\
\text { Significance }\end{array}$ \\
\hline \multicolumn{4}{|l|}{ Subject characteristics } \\
\hline Gender: no. (\%) male & $140(50)$ & $120(50)$ & $p=.9$ \\
\hline Age in years: mean $\pm S D$ & $10.9 \pm 3.2$ & $11.9 \pm 3.3$ & $p<.001$ \\
\hline Ethnicity: no. (\%) white & $272(97)$ & $228(94)$ & $p=.1$ \\
\hline Conduct disorder: no. (\%) & $41(14)$ & $4 \quad(2)$ & $p<.001$ \\
\hline \multicolumn{4}{|l|}{ Parental characteristics } \\
\hline Mother's age $^{a}:$ mean \pm SD & $29.1 \pm 4.8$ & $29.9 \pm 4.6$ & $p=.04$ \\
\hline Maternal depression: no. (\%) & $49(18)$ & $16 \quad(7)$ & $p<.001$ \\
\hline $\mathrm{ADHD}^{b}:$ no. $(\%)$ & $85(30)$ & $10 \quad(4)$ & $p<.001$ \\
\hline $\mathrm{CD} \mathrm{ASPD}^{b}:$ no. $(\%)$ & $75(27)$ & $34(14)$ & $p<.001$ \\
\hline \multicolumn{4}{|l|}{ Family and social background } \\
\hline SES: mean \pm SD & $1.9 \pm 1.0$ & $1.6 \pm 0.8$ & $p=.001^{c}$ \\
\hline Family intactness: no. (\%) & $201(72)$ & $199(82)$ & $p=.005$ \\
\hline \multicolumn{4}{|c|}{ Rutter's indicators of adversity: no. (\%) } \\
\hline None & $39(14)$ & $73(30)$ & $p<.001$ \\
\hline One & $92(33)$ & $91(38)$ & \\
\hline Two & $74(26)$ & $59(24)$ & \\
\hline Three or more & $75(27)$ & $19 \quad(8)$ & \\
\hline
\end{tabular}

Note: $\mathrm{ADHD}=$ attention-deficit hyperactivity disorder; $\mathrm{CD} / \mathrm{ASPD}=$ conduct disorder and/or antisocial personality disorder; SES $=$ socioeconomic status.

${ }^{a}$ Mother's age at time of child's birth.

${ }^{b}$ Diagnosis present in either parent.

${ }^{c}$ Nonparametric status used to calculate statistical significance. 
TABLE 2

Direct and Indirect Measures of Exposure to Cigarettes, Alcohol, and Drugs During Pregnancy

\begin{tabular}{|c|c|c|c|c|c|c|c|c|c|c|c|c|}
\hline & \multicolumn{4}{|c|}{ Total Sample } & \multicolumn{4}{|c|}{ Male Study } & \multicolumn{4}{|c|}{ Female Study } \\
\hline & \multicolumn{2}{|c|}{$\begin{array}{c}\text { ADHD } \\
\text { Cases } \\
(n=280)\end{array}$} & \multicolumn{2}{|c|}{$\begin{array}{c}\text { Non-ADHD } \\
\text { Controls } \\
(n=242)\end{array}$} & \multicolumn{2}{|c|}{$\begin{array}{c}\text { ADHD } \\
\text { Cases } \\
(n=140)\end{array}$} & \multicolumn{2}{|c|}{$\begin{array}{c}\text { Non-ADHD } \\
\text { Controls } \\
(n=120)\end{array}$} & \multicolumn{2}{|c|}{$\begin{array}{c}\text { ADHD } \\
\text { Cases } \\
(n=140)\end{array}$} & \multicolumn{2}{|c|}{$\begin{array}{l}\text { Non-ADHD } \\
\text { Controls } \\
(n=122)\end{array}$} \\
\hline & No. & $(\%)$ & No. & $(\%)$ & No. & $(\%)$ & No. & $(\%)$ & No. & $(\%)$ & No. & $(\%)$ \\
\hline \multicolumn{13}{|l|}{ Direct $^{a}$ assessment (PDIC module items) } \\
\hline $\begin{array}{l}\text { "Did you smoke as much as a pack } \\
\text { a day for at least } 3 \text { months?" }\end{array}$ & 44 & $(17)$ & 16 & $(7)$ & 31 & $(22)$ & 10 & $(8)$ & 13 & (11) & 6 & $(5)$ \\
\hline $\begin{array}{l}\text { "Did you drink an alcoholic beverage } \\
\text { daily or go on binges?" }\end{array}$ & 10 & (4) & 5 & $(2)$ & 6 & $(4)$ & 4 & (3) & 4 & (3) & 1 & $(1)$ \\
\hline $\begin{array}{l}\text { "Were you taking any drugs not } \\
\text { prescribed by a doctor?" } \\
\text { Indirect }{ }^{b} \text { assessment (maternal SCID) }\end{array}$ & 6 & (2) & 3 & $(1)$ & 4 & (3) & 2 & $(2)$ & 2 & (2) & 1 & $(1)$ \\
\hline Alcohol A/D during pregnancy & 15 & (5) & 4 & (2) & 6 & $(4)$ & 1 & (1) & 9 & (7) & 3 & (3) \\
\hline Drug A/D during pregnancy & 15 & (5) & 6 & (3) & 8 & (6) & 4 & (3) & 7 & (5) & 2 & $(2)$ \\
\hline
\end{tabular}

Note: $\mathrm{ADHD}=$ attention-deficit hyperactivity disorder; $\mathrm{PDIC}=$ the pregnancy, delivery, and infancy complications module of the structured diagnostic interview; SCID = Structured Clinical Interview for DSM-III-R; $\mathrm{A} / \mathrm{D}=$ abuse or dependence.

${ }^{a}$ Mothers were questioned directly regarding substance use during the pregnancy of the case or control child.

${ }^{b}$ Exposure to alcohol or drug A/D was determined from overlap between the reported onset and offset of the substance use disorder and the 9 months prior to the birth of the case or control child.

jects. The effects of cigarette, alcohol, and drug exposure were not significantly different for male and female subjects (Wald $\chi_{3}^{2}=0.1, p=.9$ ). There was no statistically significant association between ADHD and prenatal exposure to drugs in these data.

TABLE 3

Increased Risk for ADHD Associated With Exposure to Cigarettes, Alcohol, and Drugs During Pregnancy

\begin{tabular}{|c|c|c|c|}
\hline & Odds Ratio & $(95 \% \mathrm{CI})$ & $\begin{array}{l}\text { Statistical } \\
\text { Significance }\end{array}$ \\
\hline Cigarette exposure & 2.1 & $(1.1-4.1)$ & $p=.02$ \\
\hline Alcohol exposure ${ }^{a}$ & 2.5 & $(1.1-5.5)$ & $p=.03$ \\
\hline Drug exposure ${ }^{a}$ & 0.8 & $(0.3-2.0)$ & $p=.6$ \\
\hline $\mathrm{CD}$ in offspring & 8.5 & $(3.1-23.5)$ & $p<.001$ \\
\hline Maternal age at birth ${ }^{b}$ & 1.0 & $(0.9-1.1)$ & $p=.9$ \\
\hline Maternal depression & 1.8 & $(0.9-3.4)$ & $p=.1$ \\
\hline Parental ADHD ${ }^{c}$ & 6.6 & $(3.2-13.9)$ & $p<.001$ \\
\hline Parental CD/ASPD ${ }^{c}$ & 0.9 & $(0.5-1.6)$ & $p=.6$ \\
\hline \multicolumn{4}{|l|}{$\begin{array}{l}\text { Rutter's indicators of } \\
\text { adversity (vs. none) }\end{array}$} \\
\hline One & 1.7 & $(0.9-2.7)$ & $p=.08$ \\
\hline Two & 1.6 & $(0.9-2.8)$ & $p=.1$ \\
\hline Three or more & 4.1 & $(1.9-8.7)$ & $p<.001$ \\
\hline Subject's age in years & 0.9 & $(0.8-0.95)$ & $p<.001$ \\
\hline
\end{tabular}

Note: $\mathrm{ADHD}=$ attention-deficit hyperactivity disorder; CD/ ASPD $=$ conduct disorder and/or antisocial personality disorder.

${ }^{a}$ Bivariate measure of exposure.

${ }^{b}$ Mother's age at time of child's birth.

${ }^{c}$ Diagnosis present in either parent.

\section{DISCUSSION}

In this study we examined the effect of prenatal exposure to cigarettes, alcohol, and other drugs in ADHD cases and controls of both genders. We found (1) a twofold increased risk for ADHD associated with prenatal exposure to nicotine and smoke products, (2) a separate and independent 2.5-fold increased risk for ADHD associated with prenatal exposure to alcohol, (3) that the association between maternal smoking during pregnancy and ADHD reported in previous studies was not due to inadequate statistical control of important potential confounders, and (4) that gender did not modify the relationship between these risk factors and ADHD.

Previous studies have documented an association between academic difficulties and symptoms of inattention (Brown et al., 1991; Streissguth et al., 1984, 1994) and prenatal exposure to alcohol. In addition, others have identified a high prevalence of ADHD in a small group of children of alcoholic mothers (Aronson et al., 1997). To our knowledge, however, the present report is the first controlled study that has found prenatal exposure to alcohol abuse to increase the risk for ADHD-proper in offspring. Because none of our subjects had fetal alcohol syndrome, these findings indicate that ADHD may be an additional deleterious outcome associated with prenatal exposure to alcohol. Since this relationship was inde- 
pendent of familial ADHD and antisocial behavior disorders, our results also suggest that prenatal exposure to alcohol may cause phenocopies of ADHD (i.e., nonfamilial cases). Alternatively, it is possible that aberrant genes and environmental exposures combine to augment the risk for ADHD. More research is needed of ADHD subjects exposed and nonexposed to alcohol during pregnancy in an attempt to distinguish between these hypotheses.

The absence of a statistically significant association between prenatal exposure to drugs and ADHD was unexpected. Although this is consistent with a limited body of literature also failing to statistically detect long-term consequences of prenatal exposure to drugs (Richardson et al., 1993), it should be noted that this null finding was adjusted by exposure to alcohol and tobacco use during pregnancy and there were very few subjects exposed in our data. Thus prenatal exposure to drugs may still have an impact on the emotional and cognitive development of children, but these effects may be small and difficult to detect in the context of other risk factors which may be more noxious or more prevalent. Furthermore, we have reported in previous publications (Biederman et al., 1995b; Wilens et al., 1997) that the most prevalent type of drug abused in our adult subjects was marijuana. The lack of exposure to cocaine and other drugs known to have deleterious effects on newborns also considerably tempers our confidence in the null finding regarding prenatal exposure to drugs and the subsequent risk for ADHD.

In accord with the suggestions made in the recently reported work by Weissman et al. (1999), we adjusted for parental psychopathology and found that the relationship between ADHD and maternal smoking continued to be significant. Likewise, the well-known relationship between $\mathrm{ADHD}$ and $\mathrm{CD}$, and the reported associations between $\mathrm{CD}$ and maternal smoking during pregnancy (Fergusson et al., 1998; Wakschlag et al., 1997; Weissman et al., 1999), required that we control for comorbid CD in the index children. Again, we did not find that this potential confounder explained the relationship between ADHD and maternal smoking during pregnancy.

There was also no significant interaction between gender and prenatal exposure to cigarette smoking. This is consistent with Milberger et al. (1998), who also failed to detect a significant gender interaction when examining the association between exposure to maternal cigarette smoking during pregnancy and $\mathrm{ADHD}$ among the high-risk brothers and sisters of the male ADHD cases examined in this current report. The present report includes our previous sample of boys and a larger and independent study of girls with ADHD and provides further evidence that the effect of these exposures may not be modified by gender. This could indicate that the increased prevalence of ADHD in males is not the result of gender-specific susceptibility to teratogens such as maternal smoking or alcohol use.

Results from recent animal studies provide plausible biological mechanisms for the effects of prenatal exposure to alcohol and cigarettes found in this study. Ikonomidou et al. (2000) demonstrated that rates of apoptotic neurodegeneration in the forebrain were greater in ethanol-treated rats than in rats treated with saline. Similarly, Roy et al. (1998) found increased incidence of apoptotic cells in the hindbrain, forebrain, and midbrain of rat embryos exposed to nicotine. Damage to the developing neuroepithelium was evident at levels of prenatal exposure to nicotine that were insufficient to cause general dysmorphogenesis (Roy et al., 1998). These findings are consistent with studies documenting ADHD-related reduction in the size (Faraone and Biederman, 1999) of structures comprising the neuronal networks involved in attention (i.e., the cerebellum, basal ganglia, and right frontal lobe) (Posner and Petersen, 1990). Thus levels of exposure to nicotine and alcohol that do not affect the viability of the fetus may result in disruption of normal brain development that could lead to behavioral and attentional problems in childhood.

While these experimental animal studies are consistent with the results from our current report, we cannot definitively conclude that they explain the mechanism that underlies the association between alcohol and cigarette use during pregnancy and the risk for ADHD. Since these were controlled laboratory experiments, the administration of exposure is not directly analogous to exposure in utero resulting from parental use, for example. In addition, our measures of exposure to substance use did not allow for the estimation of a dose-response relationship or for the estimation of the timing of exposure (e.g., the specific trimester). Since both Ikonomidou et al. (2000) and Roy et al. (1998) found that the timing of exposure impacted the incidence of apoptotic cells in exposed rats, more detailed temporal information regarding exposure to cigarettes and alcohol is needed in future efforts to assess the role of cell death in the etiology of ADHD.

\section{Limitations}

First, because this is a hospital-based case-control study with retrospective assessments of exposure, these results 
are susceptible to a recall bias in which mothers of cases may have provided qualitatively different information than mothers of non-ADHD controls. It is difficult to predict in which direction this bias could impact the current findings. Mothers of children with ADHD may be motivated to identify the source of their child's disorder and therefore work to remember previous levels of exposure with greater detail; this would lead to inaccurately increased odds ratios. Alternatively, the mothers of ADHD children who used substances during pregnancy may feel guilty and tend to underestimate their true levels of use more than mothers who also used substances but whose children suffered no ill effects. In this situation the true odds ratio would have been inaccurately decreased. We attempted to deal with this bias by including information from direct questioning regarding substance use during pregnancy in which we could expect this bias to exert some effect and from a separate interview of the mother in which it was not known (to the subject or interviewer) that we would later use information collected regarding her history of substance use to recalculate in utero substance exposure. We found no statistical evidence that supported either scenario in these data, but the underlying bias may still remain. It is encouraging, however, that the odds ratio for prenatal exposure to tobacco from our hospital-based case-control study with self-reported data is consistent (2.2 versus 3.0) with the results from Landgren and colleagues' (1998) population-based case-control study, which used medical records to define exposure.

Second, available measures of exposure were limited to heavy use or abuse, did not allow for the examination of the lower doses of exposure, and did not include any measure of postnatal environmental exposure. We were limited to those questions that were asked as part of the structured diagnostic interviews. The questions-exactly as they were posed - are presented in Table 2 and indicate the lack of detail afforded in this study. Future examinations following this initial result need to estimate the effects of lower doses and the timing of exposure. Likewise, the lack of detailed information regarding the types of drugs subjects my have been exposed to limits our confidence in the lack of an effect or prenatal exposure to drugs on the risk of ADHD.

Third, replication of our findings regarding a lack of effect of gender is needed in light of differences identified by Weissman et al. (1999) and because we relied on the statistical significance of interactions which generally have little power in logistic regression models. Fourth, because our sample was ascertained via referred cases of primarily white, middle-class, intact families, our results may not generalize to children with different socioeconomic or ethnic backgrounds.

\section{Clinical Implications}

With these considerations in mind, we conclude that there may be a link between ADHD and prenatal exposure to cigarette smoking and alcohol abuse that is not an artifact of uncontrolled confounding. If upon further inquiry with prospective studies and well-quantified measures of exposure, these associations are found to be causal, maternal smoking and alcohol use during pregnancy may represent modifiable risk factors for this common psychiatric condition of childhood. If further studies of this association uncover mechanisms that lead to ADHD in children, it may be possible to develop more efficient clinical interventions. Increased research aimed at identifying the characteristics that predict smoking and alcohol abuse during pregnancy is needed to develop appropriate preventive interventions aimed at mothers-to-be.

\section{REFERENCES}

Ambrosini PJ (2000), Historical development and present status of the Schedule for Affective Disorders and Schizophrenia for School-Age Children (KSADS). J Am Acad Child Adolesc Psychiatry 39:49-58

Angold A, Costello J, Erkanli A (1999), Comorbidity. J Child Psychol Psychiatry 40:57-87

Aronson M, Hagberg B, Gillberg C (1997), Attention deficits and autistic spectrum problems in children exposed to alcohol during gestation: a followup study. Dev Med Child Neurol 39:583-587

Aronson M, Kyllerman M, Sabel KG, Sandin B, Olegard R (1985), Developmental, perceptual and behavioral characteristics as compared to matched controls. Acta Paediatr Scand 74:27-35

Biederman J, Faraone S, Mick E et al. (1999), Clinical correlates of ADHD in females: findings from a large group of girls ascertained from pediatric and psychiatric referral sources. J Am Acad Child Adolesc Psychiatry 38:966-975

Biederman J, Faraone S, Milberger S et al. (1996), A prospective 4-year follow-up study of attention-deficit hyperactivity and related disorders. Arch Gen Psychiatry 53:437-446

Biederman J, Mick E, Faraone SV et al. (2002), Influence of gender on attention deficit hyperactivity disorder in children referred to a psychiatric clinic. Am J Psychiatry 159:36-42

Biederman J, Milberger S, Faraone SV et al. (1995a), Family-environment risk factors for attention deficit hyperactivity disorder: a test of Rutter's indicators of adversity. Arch Gen Psychiatry 52:464-470

Biederman J, Newcorn J, Sprich S (1991), Comorbidity of attention deficit hyperactivity disorder with conduct, depressive, anxiety, and other disorders. Am J Psychiatry 148:564-577

Biederman J, Wilens T, Mick E, Faraone S, Spencer T (1998), Does attentiondeficit hyperactivity disorder impact the developmental course of drug and alcohol abuse and dependence? Biol Psychiatry 44:269-273

Biederman J, Wilens T, Mick E, Milberger S, Spencer T, Faraone S (1995b), Psychoactive substance use disorder in adults with attention deficit hyperactivity disorder: effects of ADHD and psychiatric comorbidity. Am J Psychiatry 152:1652-1658

Boyle M, Pickles A (1997), Influence of maternal depressive symptoms of rating of childhood behavior. J Abnorm Child Psychol 25:399-412 
Breslau N, Brown G, DelDotto J et al. (1996), Psychiatric sequelae of low birth weight at six years of age. J Abnorm Child Psychol 24:385-400

Brown RT, Coles CD, Smith IE et al. (1991), Effects of prenatal alcohol exposure at school age, II: attention and behavior. Neurotoxicol Teratol 13:369-376

Chilcoat HD, Breslau N (1997), Does psychiatric history bias mothers' reports? An application of a new analytic approach. J Am Acad Child Adolesc Psychiatry 36:971-979

Coles CD, Brown RT, Smith IE, Platzman KA, Erickson S, Falek A (1991), Effects of prenatal alcohol exposure at school age, I: physical and cognitive development. Neurotoxicol Teratol 13:357-367

Coles CD, Platzman KA, Raskind-Hood CL, Brown RT, Falek A, Smith IE (1997), A comparison of children affected by prenatal alcohol exposure and attention deficit, hyperactivity disorder. Alcohol Clin Exp Res 21:150-161

Day NL, Richardson GA, Goldschmidt L et al. (1994), Effect of prenatal marijuana exposure on the cognitive development of offspring at age three. Neurotoxicol Teratol 16:169-175

Ernst M, Moolchan ET, Robinson ML (2001), Behavioral and neural consequences of prenatal exposure to nicotine. J Am Acad Child Adolesc Psychiatry 40:630-641

Faraone SV, Biederman J (1999), The neurobiology of attention deficit hyperactivity disorder. In: Neurobiology of Mental Illness, Charney DS, Nestler EJ, Bunney BS, eds. New York: Oxford University Press, pp 788-801

Faraone SV, Biederman J, Chen WJ, Milberger S, Warburton RM, Tsuang MT (1995), Genetic heterogeneity in attention deficit hyperactivity disorder: gender, psychiatric comorbidity and maternal ADHD. J Abnorm Psychol 104:334-345

Faraone SV, Biederman J, Weiffenbach B et al. (1999), Dopamine D4 gene 7-repeat allele and attention deficit hyperactivity disorder. Am J Psychiatry $156: 768-770$

Fergusson D, Woodward L, Horwood J (1998), Maternal smoking during pregnancy and psychiatric adjustment in late adolescence. Arch Gen Psychiatry 55:721-727

Heffelfinger A, Craft S, Shyken J (1997), Visual attention in children with prenatal cocaine exposure. J Int Neuropsychol Soc 3:237-245

Hollingshead AB (1975), Four Factor Index of Social Status. New Haven, CT: Yale Press

Horton N, Laird N, Zahner G (1999), Use of multiple informant data as a predictor in psychiatric epidemiology. Int J Methods Psychiatr Res 8:6-18

Ikonomidou C, Bittigau P, Ishimaru MJ et al. (2000), Ethanol-induced apoptotic neurodegeneration and fetal alcohol syndrome. Science 287:1056-1060

LaHoste GJ, Swanson JM, Wigal SB et al. (1996), Dopamine D4 receptor gene polymorphism is associated with attention deficit hyperactivity disorder. Mol Psychiatry 1:121-124

Landgren M, Kjellman B, Gillberg C (1998), Attention deficit disorder with developmental coordination disorders. Arch Dis Child 79:207-212

Liang KY, Zeger SL (1986), Longitudinal data analysis using generalized linear models. Biometrika 73:13-22

McCartney MA, Scinto PL, Wang S, Altan S (1999), Developmental effects of phenytoin may differ depending on sex of offspring. Neurotoxicol Teratol 21:119-128

Milberger S, Biederman J, Faraone S, Chen L, Jones J (1996), Is maternal smoking during pregnancy a risk factor for attention deficit hyperactivity disorder in children? Am J Psychiatry 153:1138-1142

Milberger S, Biederman J, Faraone S, Guite J, Tsuang M (1997), Pregnancy, delivery and infancy complications and ADHD: issues of gene-environment interactions. Biol Psychiatry 41:65-75

Milberger S, Biederman J, Faraone SV, Jones J (1998), Further evidence of an association between maternal smoking during pregnancy and attention deficit hyperactivity disorder: findings from a high-risk sample of siblings. J Clin Child Psychol 27:352-358

Moos R (1985), Family Environment Scale. In: The Ninth Mental Health Measurements Yearbook, Vol 1, Mitchell JV, ed. Lincoln: Buros Institute of Mental Measurements, University of Nebraska, pp 573-575

Nanson HL, Hiscock M (1990), Attention deficits in children exposed alcohol prenatally. Alcohol Clin Exp Res 14:656-661
O'Callaghan E, Gibson T, Colohan HA et al. (1992), Risk of schizophrenia in adults born after obstetric complications and their association with early onset of illness: a controlled study. BMJ 305:1256-1259

Posner MI, Petersen SE (1990), The attention system of the human brain. Annu Rev Neurosci 13:25-42

Richardson GA, Day NL, McGauhey PJ (1993), The impact of prenatal marijuana and cocaine use on the child. Clin Obstet Gynecol 36:302-318

Roy TS, Andrews JE, Seidler FJ, Slotkin TA (1998), Nicotine evokes cell death in embryonic rat brain during neurulation.J Pharmacol Exp Ther 287:1136-1144

Rutter M, Cox A, Tupling C, Berger M, Yule W (1975), Attainment and adjustment in two geographical areas, I: the prevalence of psychiatric disorder Br J Psychiatry 126:493-509

Rutter M, Quinton D (1977), Psychiatric disorder: ecological factors and concepts of causation. In: Ecological Factors in Human Development, McGurk H, ed. Amsterdam: North Holland, pp 173-187

Sattler J (1988), Psychological Assessment, 4th ed. New York: McGraw-Hill

Shaffer D, Fisher P, Dulcan M et al. (1996), The NIMH Diagnostic Interview Schedule for Children Version 2.3 (DISC-2.3): description, acceptability, prevalence rates, and performance in the MECA study. J Am Acad Child Adolesc Psychiatry 35:865-877

Spitzer RL, Williams JB, Gibbon M, First MB (1990), Structured Clinical Interview for DSM-III-R: Non-Patient Edition (SCID-NP, Version 1.0). Washington, DC: American Psychiatric Press

Spitzer RL, Williams JB, Gibbon M, First MB (1992), The Structured Clinical Interview for DSM-III-R (SCID), I: history, rationale, and description. Arch Gen Psychiatry 49:624-629

Sprich-Buckminster S, Biederman J, Milberger S, Faraone S, Krifcher Lehman B (1993), Are perinatal complications relevant to the manifestation of ADD? Issues of comorbidity and familiality. J Am Acad Child Adolesc Psychiatry 32:1032-1037

Streissguth AP, Martin DC, Barr HM, Sandman BM, Kirchner GL, Darby BL (1984), Intrauterine alcohol and nicotine exposure: attention and reaction time in 4-year-old children. Dev Psychol 20:533-541

Streissguth AP, Sampson PD, Olson HC et al. (1994), Maternal drinking during pregnancy: attention and short-term memory in 14-year-old offspringa longitudinal prospective study. Alcohol Clin Exp Res 18:202-218

Swanson JM, Sunohara GA, Kennedy JL et al. (1998), Association of the dopamine receptor D4 (DRD4) gene with a refined phenotype of attention deficit hyperactivity disorder (ADHD): a family-based approach. Mol Psychiatry 3:38-41

Wacholder S, McLaughlin JK, Silverman DT, Mandel JS (1992a), Selection of controls in case-control studies, I: principles. Am J Epidemiol 135:1019-1028

Wacholder S, Silverman DT, McLaughlin JK, Mandel JS (1992b), Selection of controls in case-control studies, II: types of controls. Am J Epidemiol 135:1029-1041

Wacholder S, Silverman DT, McLaughlin JK, Mandel JS (1992c), Selection of controls in case-control studies, III: design options. Am J Epidemiol 135:1042-1050

Wakschlag LS, Lahey BB, Loeber R, Green SG, Gordon RA, Leventhal BL (1997), Maternal smoking during pregnancy and the risk of conduct disorder in boys. Arch Gen Psychiatry 54:670-676

Wechsler D (1974), Manual for the Wechsler Intelligence Scale for ChildrenRevised. New York: Psychological Corporation

Weissman MM, Warner V, Wickramaratne PJ, Kandel DB (1999), Maternal smoking during pregnancy and psychopathology in offspring followed to adulthood. J Am Acad Child Adolesc Psychiatry 38:892-899

Wilens TE, Biederman J, Mick E (1998), Does ADHD affect the course of substance abuse? Findings from a sample of adults with and without ADHD. Am J Addict 7:156-163

Wilens TE, Biederman J, Mick E, Faraone SV, Spencer T (1997), Attention deficit hyperactivity disorder (ADHD) is associated with early onset substance use disorders. J Nerv Ment Dis 185:475-482 